\title{
Influence of Metallic Powder Contents on Corrosion Resistance of Galvanized Steel with Metal Powder-containing Organic Coatings for Automobile Fuel Tanks
}

\author{
Hiroyuki OGATA ${ }^{1) *}$ and Hiroki HABAZAKI ${ }^{2)}$ \\ 1) Planning Department, Functional Materials Solution Division, JFE Techno-Research Corp., Chiba, Chiba, $260-0835$ Japan. \\ 2) Division of Applied Chemistry, Faculty of Engineering, Hokkaido University, Sapporo, Hokkaido, 060-8628 Japan.
}

(Received on April 27, 2017; accepted on July 28, 2017; J-STAGE Advance published date: October 17, 2017)

\begin{abstract}
$\mathrm{Pb}$ - and $\mathrm{Cr}(\mathrm{VI})$-free galvanized steel sheets for fuel tanks are coated with epoxy-resin films (thickness: approx. $3 \mu \mathrm{m}$ ) containing particulate Ni powder and flaky Al powder to provide a combination of weldability and degraded gasoline resistance (sour gasoline resistance). The corrosion behavior of galvanized steel specimens coated with epoxy resin containing different amounts of the two types of metal powders was investigated in a solution containing acetic acid, formic acid and $\mathrm{NaCl}$ at $\mathrm{pH} 3.2$ and $40^{\circ} \mathrm{C}$ to elucidate the mechanism of corrosion protection by the coatings. The oxygen gas permeability and water vapor permeability of the coatings were also examined. The results indicated that the addition of particulate $\mathrm{Ni}$ powder promoted galvanic corrosion between the $\mathrm{Ni}$ and the $\mathrm{Zn}$ coating. Voids generated around the embedded $\mathrm{Ni}$ powder particles also appeared to accelerate the penetration of the corrosive solution through the coating. On the other hand, the addition of the flaky Al powder improved corrosion resistance. This improved corrosion resistance is associated with the suppression of direct contact between the $\mathrm{Ni}$ powder and the Zn coating and also with increased barrier properties, which could be confirmed from oxygen gas and water vapor permeation measurements.
\end{abstract}

KEY WORDS: fuel tank; organic coating; corrosion; flaky aluminum powder; particulate nickel powder; oxygen permeability; water vapor permeability.

\section{Introduction}

$\mathrm{A} \mathrm{Pb}-\mathrm{Sn}$ alloy-coated steel sheet has been used as a main material for automobile fuel tanks. Despite the satisfactory properties of the coated steel for fabrication and use in fuel tanks, the coating contains toxic $\mathrm{Pb}$ in the amount of 90 mass $\%$, and the use of $\mathrm{Pb}$ has been restricted in the automobile industry because of tightened environmental regulations in the last decades. The Japan Automobile Manufacturers Association, Inc. proposed to reduce the amount of $\mathrm{Pb}$ used in the automobile industry to half or less of that in 1996 by the end of 2000 or to one-third or less by the end of 2005. ${ }^{1)}$ The EU also restricted the use of $\mathrm{Cr}(\mathrm{VI})$ under Directive 2000/53/EU enacted in October 2000. Chromate treatments have been widely used for surface treatment of various practical metallic materials, including $\mathrm{Pb}-\mathrm{Sn}$ alloy-coated steels, zinc-coated steels and aluminum alloys, but the amount of $\mathrm{Cr}(\mathrm{VI})$ used in a car has been restricted to $2 \mathrm{~g}$ or less for newly-registered cars in the EU since July 2003. In accord with the above-described environmental regulations, $\mathrm{Pb}$-free and $\mathrm{Cr}(\mathrm{VI})$-free steel materials for fuel tanks have been developed since the late 1990 s. $^{2}$

* Corresponding author: E-mail: h-ogata@jfe-tec.co.jp DOI: http://dx.doi.org/10.2355/isijinternational.ISIJINT-2017-244
Figure 1 is an example of the $\mathrm{Pb}$ - and $\mathrm{Cr}(\mathrm{VI})$-free steel for fuel tanks, which consists of electrogalvanized zinc layers and $\mathrm{Cr}(\mathrm{VI})$-free $\mathrm{Cr}(\mathrm{III})$ oxide layers on both sides of

$\downarrow$ The surface used as the outside of the tank

Lubricating coating $1 \mu \mathrm{m}$

$\mathrm{Cr}(\mathrm{III})$ film $0.1 \mu \mathrm{m}$

Electro-galvanized layer $5 \mu \mathrm{m}$

Cold-rolled steel sheet

Electro-galvanized layer $5 \mu \mathrm{m}$ $\mathrm{Cr}(\mathrm{III})$ film $0.1 \mu \mathrm{m}$

Gasoline resistant coating $3 \mu \mathrm{m}$

$\uparrow$ The surface used as the inside of the tank Coating main component

$$
\left(\begin{array}{l}
\text { (1)Epoxy resin } \\
\text { (2)Particulate nickel powder } \\
\text { (3)Flaky aluminum powder }
\end{array}\right)
$$

Fig. 1. Schematic illustration of environmental harmonization $(\mathrm{Pb}, \mathrm{Cr}(\mathrm{VI})$-free) fuel tank materials. 
the cold-rolled steel sheet. Furthermore, an organic layer of $1 \mu \mathrm{m}$ thickness is coated on the outside of the tank to provide lubricating properties, while an epoxy film containing $\mathrm{Ni}$ and $\mathrm{Al}$ powders is coated on the inside of the tank to ensure sufficient welding properties and high stability in deteriorated gasoline. Figure $\mathbf{2}$ shows a schematic illustration of the shape of a typical fuel tank and summarizes the required properties of the tank material. The fuel tank consists of an upper tank shell and lower tank shell; both are formed by press forming and are then seam-welded together. A reserve cup is spot-welded to the lower tank shell. Thus, press formability, seam weldability and spot weldability are required in the tank material.

Formic acid and acetic acid are formed through the oxidation and degradation of alkenes, which are main constituents of gasoline. ${ }^{3)}$ These acids are dissolved in dew condensation water, which also contains sea salt derived from the outer air environment. Thus, the tank material is exposed to a corrosive aqueous environment containing formic acid, acetic acid and chloride ions. Since the zinc coating corrodes in aqueous solutions containing these acids and chloride, ${ }^{4,5)}$ organic coating of the zinc-coated steel is indispensable for corrosion protection. ${ }^{6)}$ However, insulating organic coatings such as epoxy coatings show no weldability when applied in thicknesses of several micrometers. ${ }^{7)}$ For this reason, metallic powders have been added to these epoxy coatings to improve weldability. It is known that weldability decreases as the particle size of iron powder becomes finer, and weldability is improved by adding metal particles larger than the coating thickness. ${ }^{8)}$ The addition of Ni particles in the epoxy coating is effective for obtaining sufficient weldability, but the corrosion resistance of the zinc-coated steel decreases when the amount of $\mathrm{Ni}$ powder included in the epoxy coating increases. To solve this problem, an epoxy coating containing both particulate Ni powder and flaky Al powder has been developed and used practically in the automobile industry, since this coating shows sufficient weldability and corrosion resistance in the environments inside fuel tanks. ${ }^{2}$ ) However, the mechanism of the corrosion resistance of coatings containing both $\mathrm{Ni}$ and $\mathrm{Al}$ powders and the influence of the amounts of $\mathrm{Ni}$ and $\mathrm{Al}$ powders in the coating were not well understood.

Therefore, in this study, we examined the corrosion behavior of electrogalvanized steel with epoxy resin coatings containing various amounts of $\mathrm{Ni}$ and $\mathrm{Al}$ powders, and discussed the role of the $\mathrm{Ni}$ and $\mathrm{Al}$ powders in corrosion

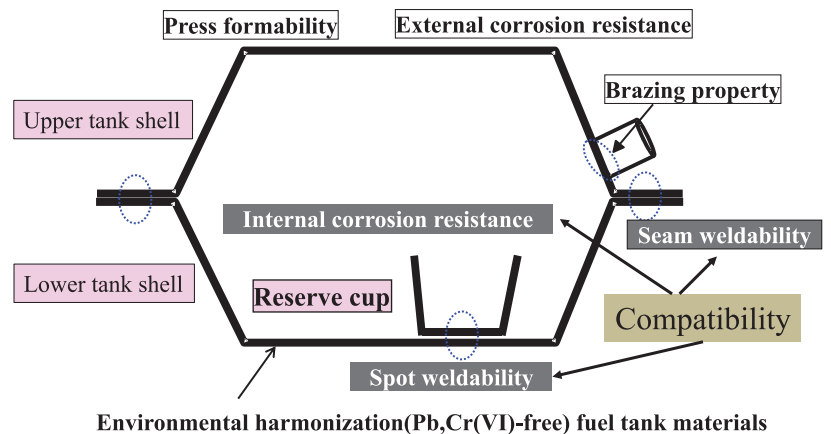

Fig. 2. Required properties for fuel tank materials. (Online version in color.) protection through a detailed characterization of the coatings and permeability measurements of oxygen gas and water vapor.

\section{Experimental}

\subsection{Materials}

The substrate used in this study was an electrogalvanized cold-rolled steel with a zinc layer of approximately $40 \mathrm{~g} \mathrm{~m}^{-2}$ on both sides. After alkaline degreasing with a reagent of CLN 364 S, manufactured by Nippon Parkerizing Co., Ltd., a $\mathrm{Cr}$ (III) layer containing $40 \mathrm{mg} \mathrm{m}^{-2} \mathrm{Cr}$ (III) was formed using a coating solution containing $\mathrm{Cr}(\mathrm{VI})$ species, which completely converted to $\mathrm{Cr}$ (III) in the coating layer. After coating by a wire bar coating method, heat treatment was performed at $100^{\circ} \mathrm{C}$. Epoxy coatings containing various amounts of $\mathrm{Ni}$ powder particles of 3-7 $\mu \mathrm{m}$ size and $\mathrm{Al}$ powder flakes with dimensions of $18 \mu \mathrm{m}$ in the long diameter, $5 \mu \mathrm{m}$ in the short diameter and $1 \mu \mathrm{m}$ in thickness were prepared by a wire bar coating method at $150^{\circ} \mathrm{C}$. The average coating thickness was $3 \mu \mathrm{m}$. In this paper, the amount of the added $\mathrm{Ni}$ and $\mathrm{Al}$ powders is expressed as parts per hundred resin (phr), i.e., the weight of the $\mathrm{Ni}$ or $\mathrm{Al}$ powder with respect to 100 parts by weight of epoxy resin. For instance, $20 \mathrm{phr}$ Ni means that $20 \mathrm{~g}$ of Ni powder are added to $100 \mathrm{~g}$ of epoxy resin.

\subsection{Corrosion Tests}

The corrosion resistance of the coated electrogalvanized steel specimens was examined in a $\mathrm{pH} 3.2$ aqueous solution containing $100 \mathrm{ppm}$ formic acid, $100 \mathrm{ppm}$ acetic acid and 83 ppm $\mathrm{NaCl}$ at $40 \pm 1^{\circ} \mathrm{C}$. This solution was used to simulate the corrosive environment in a fuel tank. ${ }^{9,10)}$ The coated specimens were cut to $30 \mathrm{~mm} \times 80 \mathrm{~mm}$, and the back side and edges of the specimens were masked with adhesive tape to expose only the front side of the specimens to the solution. As shown in Fig. 3, the bottom two-thirds of the specimen was immersed in the solution, and the remaining top part was exposed to a vapor phase. After immersion for various periods of time, the specimens were washed in distilled water and dried under hot air. Their corrosion resistance was evaluated by measuring the corroded area ratio with GIMP 2.8.18 software (GNU Image Manipulation Program).

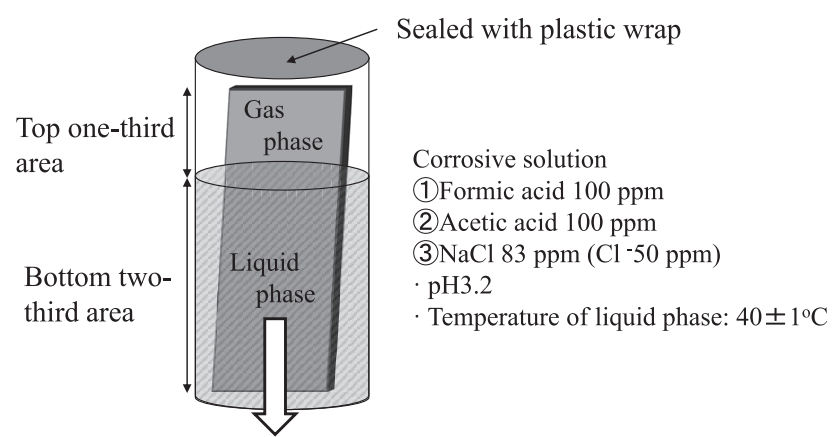

Photographs were taken after the corrosion resistance test and digitized to obtain numerical values to determine corroded area ratio.

Fig. 3. Schematic illustration of immersion corrosion test in this study. 


\subsection{SEM Observation}

Prior to cross-sectional SEM observation of the specimens, a thin Pt-Pd alloy layer was coated on the specimen surface. After embedding the specimens in epoxy resin, cross-sections suitable for SEM observations were obtained by mechanical polishing. In some cases, a JEOL IB19510CP cryo-cross-section polisher was used to prepare the cross-sections in order to reduce the damage by mechanical polishing. The cross-sections thus prepared were observed by using a JEOL JSM7100F field emission gun scanning electron microscope operated at 3.0 or $5.0 \mathrm{kV}$. For elemental mapping by energy-dispersive X-ray spectroscopy (EDS), the accelerating voltage was increased to $15.0 \mathrm{kV}$.

\subsection{Oxygen Gas and Water Vapor Permeation Mea- surements}

For the oxygen gas and water vapor permeation measurements, epoxy resin coatings containing $\mathrm{Ni}$ and $\mathrm{Al}$ powders were painted on a polyimide film (Kapton $500 \mathrm{H}$ manufactured by Du Pont-Toray Co. Ltd.) of $125 \mu \mathrm{m}$ thickness by a wire bar coating method. Thicker coatings of $30 \mu \mathrm{m}$ thickness were used for the oxygen and water vapor permeation measurements to obtain a sufficiently large difference of gas permeability between the polyimide films with and without coating. An O-well Corp. Omegatrans gas permeation measurement system was used for both the oxygen gas and water vapor permeation measurements. Figure 4 shows the principle of the gas permeability measurements. The chamber was separated by a sample sheet (Fig. 4(b)) into gas introduction and permeated gas measurement sections, and the oxygen gas and water vapor that permeated through the coating were monitored by a quadrupole mass spectrometer (QMS). Water vapor permeability was measured at $40^{\circ} \mathrm{C}$, $90 \%$ relative humidity and gas pressure of $6.8 \mathrm{kPa}$, and oxygen gas permeability was measured at $40^{\circ} \mathrm{C}, 90 \%$ relative humidity and an oxygen gas pressure of $100 \mathrm{kPa}$. The sample areas for both measurements were $40 \mathrm{~mm}$ in diam- eter. Prior to the gas permeation measurements, a calibration curve was obtained by the standard conductance element method proposed by Yoshida et al. ${ }^{11)}$ to quantify the amount of water vapor or oxygen gas permeated through the sample sheet by the QMS. As shown in Fig. 4(a), the calibration was conducted without introducing the sample sheet.

\section{Experimental Results}

\subsection{Corrosion Resistance}

Figure 5 shows the surface appearance of the specimens after the immersion test. Corrosion resistance is obviously improved by the addition of the $\mathrm{Al}$ powder in the coating containing $40 \mathrm{phr} \mathrm{Ni}$. The area surrounded by the black square was immersed in the solution. Many corroded areas (darker appearance) are present in the immersed region of specimen (A) with $40 \mathrm{phr} \mathrm{Ni}$ and no Al. Corrosion of this specimen also occurs in the vapor-exposed region above the immersed area. In both regions, the corroded area ratio clearly decreases with an increase in the amount of $\mathrm{Al}$ powder.
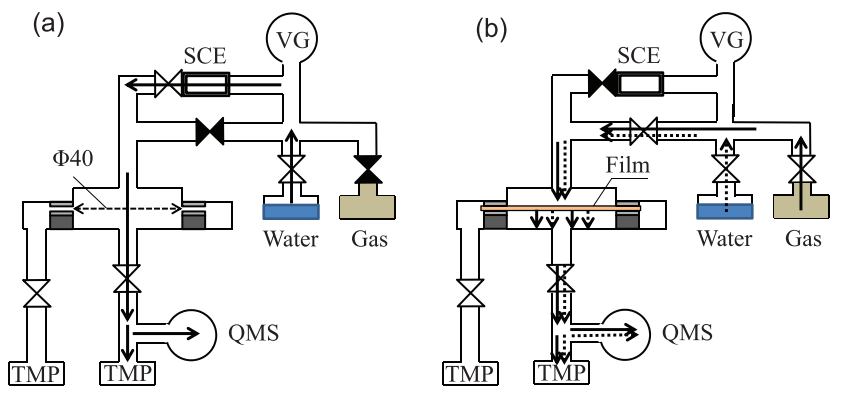

Fig. 4. Schematic illustrations of gas permeation measurements; (a) for calibration of amounts of water vapor and oxygen gas introduced into the chamber and (b) water vapor and oxygen gas permeation. SCE: Standard Conductance Element, VG: Vacuum Gauge, QMS: Quadrupole Mass Spectrometer, TMP: Turbomolecular Pump. (Online version in color.)

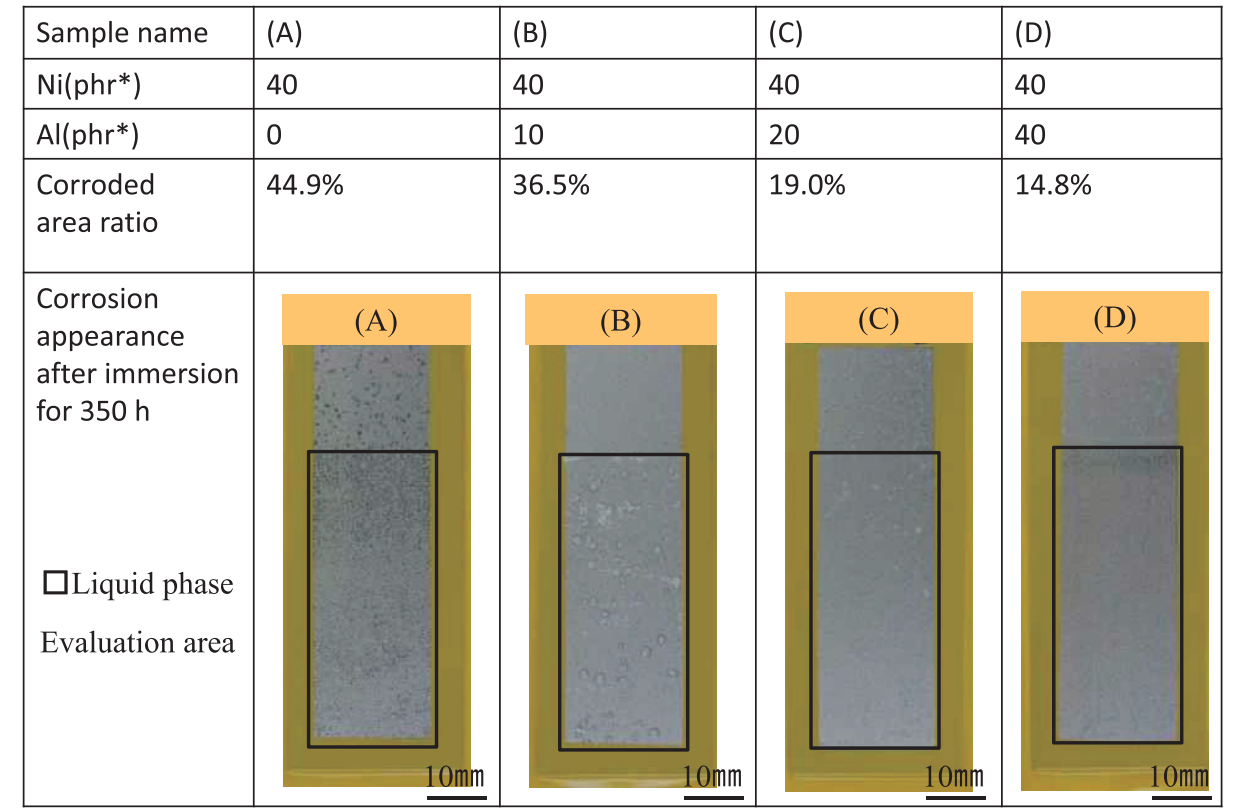

Fig. 5. Surface appearance of samples (A) to (D) immersed in corrosive solution containing 100 ppm formic acid, 100 ppm acetic acid and $83 \mathrm{ppm} \mathrm{NaCl}$ at $40^{\circ} \mathrm{C}$ for $350 \mathrm{~h}$. * per hundred resin 
The corroded area ratio of each specimen was estimated from the image analysis of the immersed regions. Figure 6 shows the change in the average corroded area ratio of the coated steel specimens with the amount of $\mathrm{Al}$ powder. The corroded area ratio was only up to $8 \%$ for the coated electrogalvanized steel without $\mathrm{Ni}$ and $\mathrm{Al}$ powders, and a corroded area was not clearly detected when only Al powder was added to the epoxy coating. In contrast, addition of $\mathrm{Ni}$ powder greatly increased the corroded area ratio from $8 \%$ to $30-45 \%$. No clear dependence of the corroded area ratio on the amount of Ni powder can be seen in Fig. 6, partly because of large variations of the corroded area ratio of the $\mathrm{Ni}$-containing coatings. Although the addition of $\mathrm{Ni}$ powder was detrimental to corrosion resistance, simultaneous addition of $\mathrm{Al}$ powder improved corrosion resistance. Regardless of the amount of $\mathrm{Ni}$ powder, the corroded area ratio decreased with an increase in the amount of $\mathrm{Al}$ powder. The corroded area is reduced to $10 \%$ or less at $40 \mathrm{phr}$ of $\mathrm{Al}$ when the amount of $\mathrm{Ni}$ powder is $20 \mathrm{phr}$, being comparable to that of the epoxy coating containing no $\mathrm{Ni}$ and $\mathrm{Al}$ powders.

\subsection{Observations of Corroded Specimens}

Figure 7 shows SEM images of the cross-sections of corroded and non-corroded regions of the coated steel with $40 \mathrm{phr} \mathrm{Ni}$ and $10 \mathrm{phr} \mathrm{Al}$ (Sample (B) in Fig. 5). It is evident that $\mathrm{Ni}$ powder is located in the coating on the corroded Zn layer (Fig. 7(a)). Similarly, Ni powder was often found

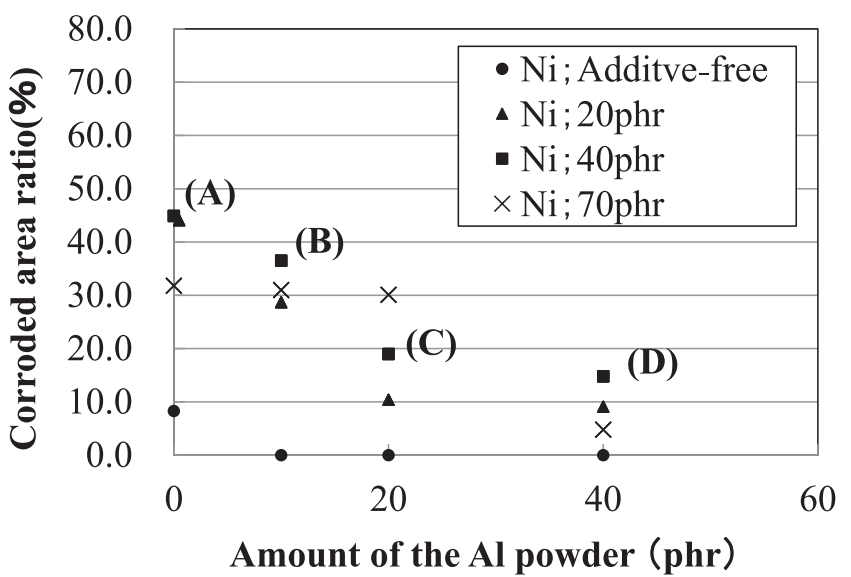

Fig. 6. Correlation between corroded area ratio and amount of $\mathrm{Al}$ and Ni powders after immersion in corrosive solution containing $100 \mathrm{ppm}$ formic acid, $100 \mathrm{ppm}$ acetic acid and 83 ppm $\mathrm{NaCl}$ at $40^{\circ} \mathrm{C}$ for $350 \mathrm{~h}$.

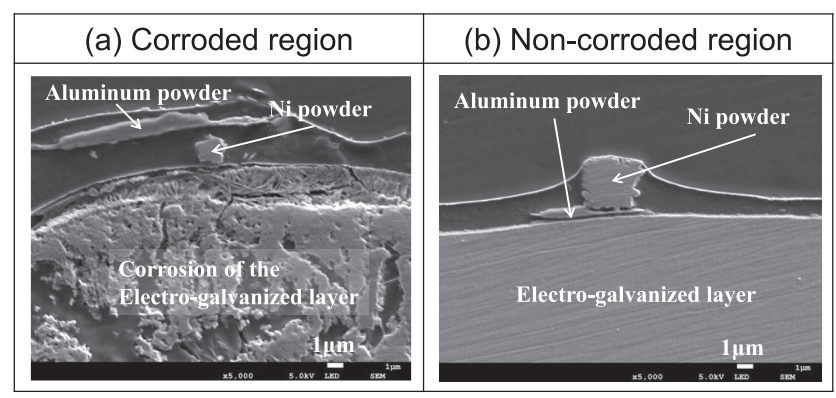

Fig. 7. Cross-sectional SEM images of corroded and non-corroded regions of sample (B) (40 phr Ni and $10 \mathrm{phr} \mathrm{Al})$ after immersion in corrosive solution containing $100 \mathrm{ppm}$ formic acid, $100 \mathrm{ppm}$ acetic acid and $83 \mathrm{ppm} \mathrm{NaCl}$ at $40^{\circ} \mathrm{C}$ for $350 \mathrm{~h}$. in the coating above corroded $\mathrm{Zn}$ regions. It is, therefore, likely that the accelerated corrosion by the addition of $\mathrm{Ni}$ is due to the formation of a galvanic couple between the $\mathrm{Ni}$ powder and the $\mathrm{Zn}$ layer. In the non-corroded region, flaky $\mathrm{Al}$ powder particles were often located at the bottom of the coating and prevented direct contact between the Ni powder and the $\mathrm{Zn}$ layer, as shown in Fig. 7(b).

Figure 8 shows the EDS images of $\mathrm{O}, \mathrm{Al}$ and $\mathrm{Ni}$ in Fig. 7(a). Obviously, the small particle on the corroded $\mathrm{Zn}$ layer is Ni and the flaky material at the top of the paint layer is Al. Oxygen is present in the $\mathrm{Zn}$ layer, which appears at the bottom of the micrograph, confirming the corrosion of the $\mathrm{Zn}$ layer. The oxidation of the Al flakes and Ni powder is less significant compared with that of $\mathrm{Zn}$, as seen in the EDS image of $\mathrm{O}$.

In order to examine the distributions of the $\mathrm{Ni}$ and $\mathrm{Al}$ powders in the epoxy coatings further, cross-sections of the coatings containing $40 \mathrm{phr} \mathrm{Ni}$ and $10 \mathrm{phr}$ Al (Sample (B) in Fig. 5) and $40 \mathrm{phr} \mathrm{Ni}$ and $40 \mathrm{phr}$ Al (Sample (D) in Fig. 5) were observed before the corrosion test (Fig. 9). In sample (B) containing $40 \mathrm{phr} \mathrm{Ni}$ and $10 \mathrm{phr} \mathrm{Al}$, the $\mathrm{Ni}$ powder particles were in direct contact with the $\mathrm{Zn}$ layer,

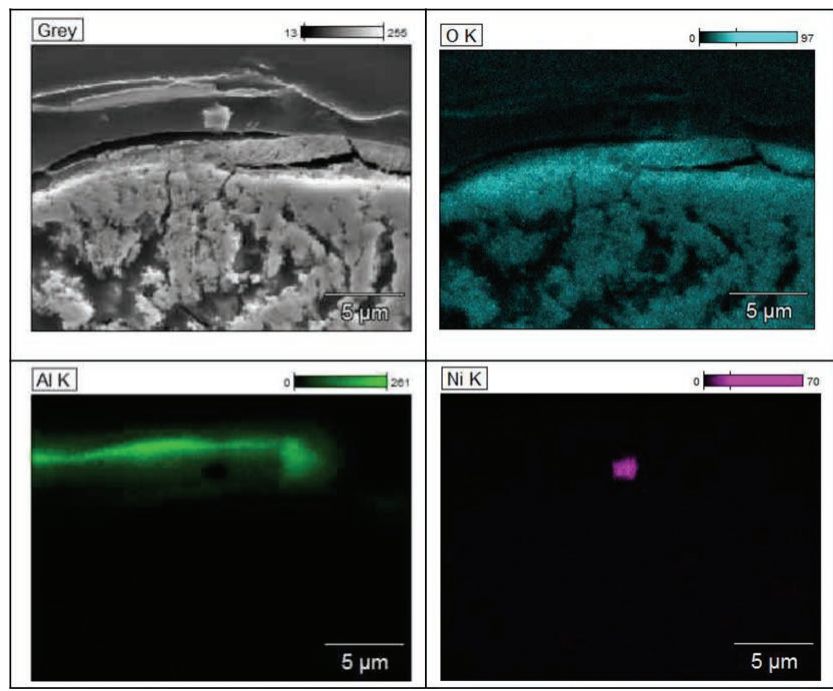

Fig. 8. Cross-sectional SEM and $\operatorname{EDX}(\mathrm{O}, \mathrm{Al}$, and $\mathrm{Ni})$ images of corroded area (Fig. 7(a)). (Online version in color.)

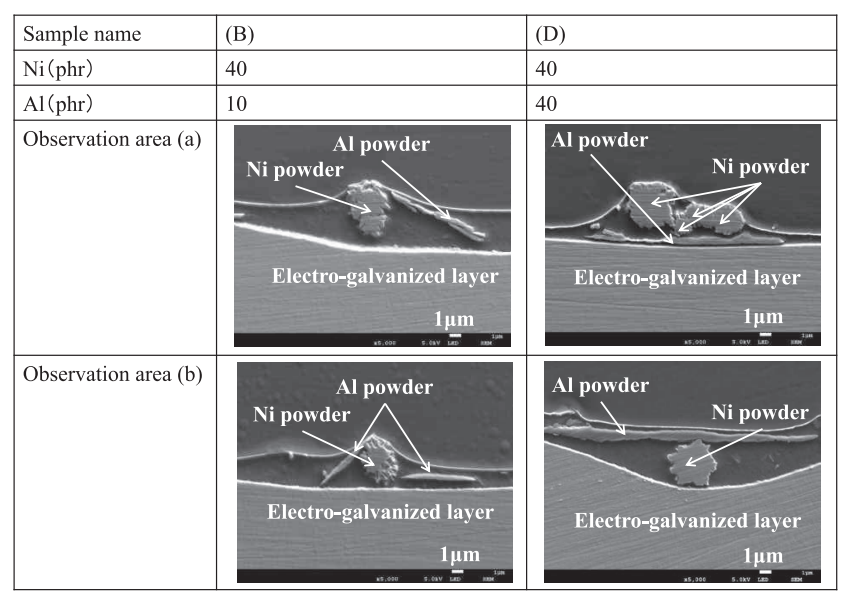

Fig. 9. Cross-sectional SEM observation results for samples (B) (40 phr Ni and $10 \mathrm{phr}$ Al) and (D) (40 phr Ni and $40 \mathrm{phr}$ Al) before corrosion test. 
as shown in the image of area (b) of sample (B) in Fig. 9. When the amount of $\mathrm{Al}$ increased to $40 \mathrm{phr}$, flaky $\mathrm{Al}$ powder particles were often located at the bottom of the coating and prevented direct contact between the Ni powder and the Zn layer, as shown in area (a) of sample (D). This area was also examined by EDS (Fig. 10). Apparently, an Al flake is in contact with the lower $\mathrm{Zn}$ layer as well as the upper $\mathrm{Ni}$ powder. In contrast to the images in Fig. 8, oxygen is hardly detected in the $\mathrm{Zn}$ layer except at the $\mathrm{Zn}$ layer surface. Thus, the corrosion of the $\mathrm{Zn}$ layer is effectively suppressed when the Al flake is located immediately above the $\mathrm{Zn}$ layer. The oxygen EDS image in Fig. 10 reveals only slight oxidation of the Al flake, even if the flake is in contact with a Ni powder particle. The Ni powder is also not oxidized severely in this coating. Even when the Al content in the epoxy coating was increased to $40 \mathrm{phr}$, Ni powder particles were in contact with the $\mathrm{Zn}$ layer, as shown in area (b) of sample (D) in Fig 9. After the corrosion test, no corrosion was found near the $\mathrm{Ni}$ particle covered with $\mathrm{Al}$ powder. We observed $34 \mathrm{Ni}$ powder particles in the epoxy coating of sample (D) before the corrosion test, and 62\% of the Ni powder particles were located above the flaky Al powder, as in area (a) of this sample (Fig. 9). As shown in Fig. 7(b), no corrosion occurred when the flaky Al powder was located between the Zn layer and Ni powder. The corroded area ratio of the coating with $40 \mathrm{phr} \mathrm{Ni}$ was reduced to approximately one-third by the addition of $40 \mathrm{phr} \mathrm{Al}$ (Fig. 6 ). The reduction of the corroded area ratio is approximately consistent with the number ratio of the Ni powder particles located on the Al powder flakes. The number of Ni powder particles covered with Al powder was only one. The very limited number of $\mathrm{Ni}$ particles covered by an $\mathrm{Al}$ powder flake suggests that this configuration of particles has little influence on overall corrosion.

\subsection{Gas Permeation Measurements}

The influence of the $\mathrm{Ni}$ and $\mathrm{Al}$ powders on the oxygen gas and water vapor permeability of the coatings was examined. The gas permeation rate of the polyimide films was measured with and without an epoxy coating. The gas

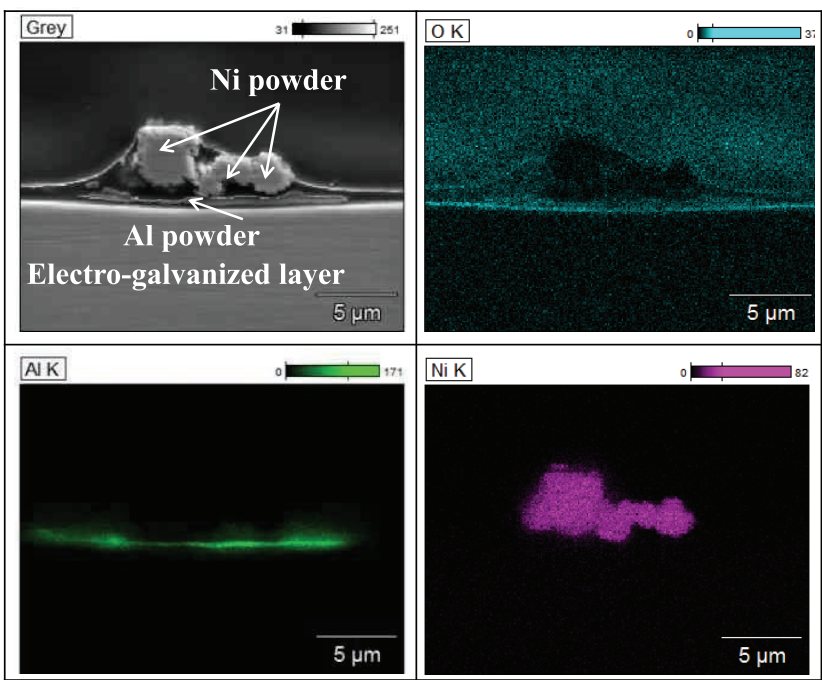

Fig. 10. Cross-sectional SEM and $\operatorname{EDX}(\mathrm{O}, \mathrm{Al}$, and $\mathrm{Ni})$ images of observation area (a) of sample (D) in Fig. 9. (Online version in color.) permeation rate was reduced by the coating, such that the difference of the gas permeation rates for the polyimide films with and without the coating, i.e., the decrease in the permeation rate by the coating ( $\triangle \mathrm{OPR}$ for oxygen and $\Delta$ WPR for water), was plotted as an oxygen and water vapor permeation barrier characteristic. $\triangle \mathrm{OPR}$ and $\Delta \mathrm{WPR}$ are defined as follows.

$$
\begin{aligned}
& \Delta \mathrm{OPR}=\Delta \mathrm{OPR}(\mathrm{PI})-\Delta \mathrm{OPR}(\mathrm{PI}+\text { coating }) \\
& \Delta \mathrm{WPR}=\Delta \mathrm{WPR}(\mathrm{PI})-\Delta \mathrm{WPR}(\mathrm{PI}+\text { coating })
\end{aligned}
$$

where $\Delta \mathrm{OPR}(\mathrm{PI})$ and $\Delta \mathrm{OPR}(\mathrm{PI}+$ coating) are the oxygen gas permeation rates of polyimide films without and with a coating, respectively. Similarly, $\triangle \mathrm{WPR}(\mathrm{PI})$ and $\Delta \mathrm{WPR}$ (PI+coating) are the respective water vapor permeation rates.

Figure 11(a) shows the change in $\triangle \mathrm{OPR}$ with the amount of flaky $\mathrm{Al}$ powder. $\triangle \mathrm{OPR}$ increases with an increase in the amount of Al. With the Al-free epoxy coatings, the oxygen permeability of the Ni-free coating is similar to that with $20 \mathrm{phr} \mathrm{Ni}$, but a further increase in the amount of $\mathrm{Ni}$ results in an increase in oxygen permeability. Even with the Al-containing coatings, oxygen permeability is enhanced by the addition of Ni powder at $\geq 40 \mathrm{phr}$ Ni. This is probably associated with the presence of voids around the Ni powders. Figure 12 shows a cross-section of the epoxy
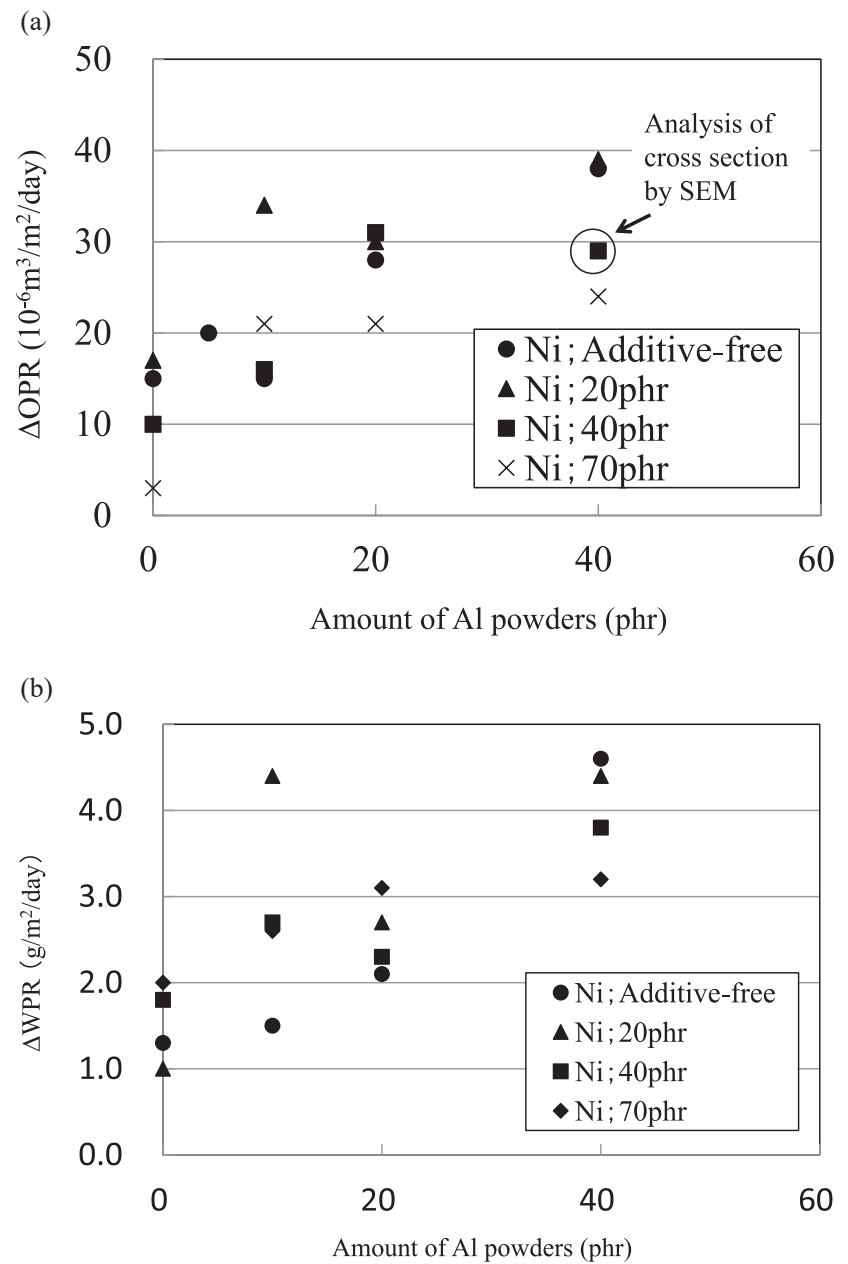

Fig. 11. Relationship between (a) oxygen gas and (b) water vapor barrier properties and amount of $\mathrm{Al}$ and $\mathrm{Ni}$ powders at $40^{\circ} \mathrm{C}$, relative humidity of $90 \%$ and $100 \mathrm{kPa}$. 


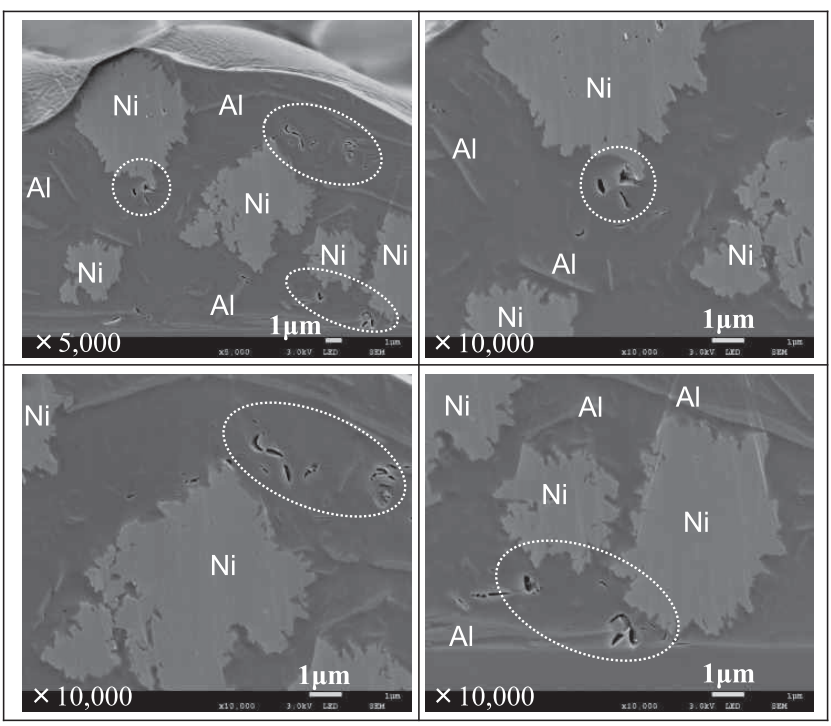

Fig. 12. Cross-sectional SEM images of coating containing 40 phr Ni and $40 \mathrm{phr} \mathrm{Al}$ on polyimide film. Areas with voids are indicated by circles.

coating containing $40 \mathrm{phr} \mathrm{Ni}$ and $40 \mathrm{phr} \mathrm{Al}$. As shown in this micrograph, voids were often found in the epoxy resin near the Ni powders, but not around Al powders. It is likely that the irregular shaped Ni powder induces the formation of these voids and thereby enhances the gas permeability. The permeability of water vapor was also examined (Fig. 11(b)). Similar to oxygen permeability, we found that water vapor permeability decreased with an increase in the amount of Al powder.

\section{Discussion}

\subsection{Effect of Al Powder Addition on Corrosion Resis- tance}

Compared with the coating containing no $\mathrm{Ni}$ or $\mathrm{Al}$ powder, the addition of Ni powder deteriorates corrosion resistance. The cross-sectional SEM observations of the corroded regions disclose severe corrosion of the $\mathrm{Zn}$ layer around the $\mathrm{Ni}$ powder. However, the simultaneous addition of Al powder together with Ni powder improves corrosion resistance; namely, the number of corroded regions is greatly reduced by the addition of Al. The cross-sectional SEM observations revealed that $\mathrm{Al}$ powder flakes were often sandwiched between the Ni powder and the $\mathrm{Zn}$ layer, and no corrosion of the $\mathrm{Zn}$ layer was found in such regions.

As shown in Fig. 7(a), severe corrosion of the $\mathrm{Zn}$ layer occurs around the Ni powder in the present corrosive environment, probably because of galvanic corrosion, while corrosion of the Al powder is less significant. Although $\mathrm{Al}$ is less noble than $\mathrm{Ni}$, no severe corrosion of $\mathrm{Al}$ powder was found in this study even when an Al powder particle was in contact with a Ni powder particle. This suggests that Al has relatively high corrosion resistance in the present corrosive environment, and corrosion appeared not to be accelerated by contact between $\mathrm{Al}$ powder and $\mathrm{Ni}$ powder. Thus, the introduction of corrosion-resistant and less-noble flaky Al powder between the Ni powder particles and the $\mathrm{Zn}$ layer is effective in suppressing galvanic corrosion between $\mathrm{Zn}$ and Ni. It was reported that corrosion resistance increases in the following order: $\mathrm{Zn}<\mathrm{Zn}-55 \% \mathrm{Al}<\mathrm{Al}$, and a transformation from linear to parabolic kinetics was found by $\mathrm{Zn}$ alloying with $\mathrm{Al} .{ }^{12)}$ Mansfeld et al. measured the galvanic current of $\mathrm{Al}$ alloys coupled with various metals in a 3.5\% $\mathrm{NaCl}$ solution. ${ }^{13)}$ The galvanic current was rather low for the $\mathrm{Al} / \mathrm{Zn}$ couple, and a higher galvanic current was found in the $\mathrm{Al}$ alloy/Ni couple $\left(11-22 \mu \mathrm{A} \mathrm{cm}{ }^{-2}\right)$. Thus, the $\mathrm{Ni}$ accelerated the corrosion of $\mathrm{Al}$ alloys in the more corrosive solution containing a higher concentration of chloride ions, but in the present corrosive environment containing only $50 \mathrm{ppm}$ chloride ions, no severe acceleration of corrosion of the Al powder was found.

When the amount of added Al powders was relatively high, the corrosion of the $\mathrm{Zn}$ layer was suppressed even when the Ni powder was in direct contact with the Zn layer, as shown in region (b) of sample (D) (Fig. 9). The oxygen gas and water vapor permeation measurements revealed that the barrier nature of the paint coatings was enhanced with an increase in the amount of flaky Al powder. The Al powder with dimensions of $18 \mu \mathrm{m}$ in the long diameter and $5 \mu \mathrm{m}$ in the short diameter effectively suppressed the penetration of the corrosive solution to the underlying $\mathrm{Ni}$ powder and Zn layer, probably by a labyrinth effect, contributing to prevention of corrosion. However, this configuration of the $\mathrm{Ni}$ and $\mathrm{Al}$ powders in the coating was very limited, such that the main contribution to corrosion suppression is the introduction of $\mathrm{Al}$ powder flakes between the $\mathrm{Zn}$ layer and Ni powder to prevent galvanic corrosion. The improved gas barrier property obtained by introduction of $\mathrm{Al}$ powder may also contribute to the improved corrosion resistance of the coated steel.

\subsection{Effect of Ni Powder Addition on Corrosion Resis- tance}

It is evident from Fig. 6 that the addition of Ni powder to an epoxy coating is detrimental to corrosion resistance. Although the corrosion resistance of Ni-containing coatings is improved by the addition of $\mathrm{Al}$ powder, the corroded area ratio of the Ni-containing coatings is higher than that of the $\mathrm{Ni}$-free ones when the same amount of $\mathrm{Al}$ powder is present. There are two main reasons for the accelerated corrosion of the Ni-containing coatings. One is galvanic corrosion between the Ni powder particles and the $\mathrm{Zn}$ layer. As shown in Fig. 7(a), the corrosion of the Zn layer is severe near a $\mathrm{Ni}$ powder particle. It is known that the dissolution of $\mathrm{Zn}$ is accelerated by a $\mathrm{Zn} / \mathrm{Fe}$ couple. ${ }^{14-17)}$ Since $\mathrm{Ni}$ is nobler than $\mathrm{Fe}$, it is likely that galvanic corrosion of $\mathrm{Zn}$ in contact with $\mathrm{Ni}$ powder occurs in this study, although it has also been reported that a $\mathrm{Zn}-\mathrm{Ni}$ solid-solution alloy showed a slower corrosion rate than $\mathrm{Zn}^{18)}$

The other reason for the increased corrosion by the addition of $\mathrm{Ni}$ is the increased gas permeability of the epoxy coatings. The epoxy coating contains voids near the Ni powder particles, as shown in Fig. 12. The Ni powder particles used in this study have many spike-like protrusions on their surfaces. Gas remained in the gaps between these spikes of the Ni powder in the resin solution, and then formed voids around the Ni powder after evaporation of the solvent during heat treatment. The number of voids increases with the amount of $\mathrm{Ni}$ powder particles, leading to increased oxygen gas and water vapor permeability through the voids 
(Fig. 12). The voids should also increase the permeation of the corrosive solution, reducing the corrosion protection properties of the coatings. Since such voids were not observed around the flaky Al powder, it is likely that the formation of voids is associated with the spike-like shape of the Ni powder. Thus, is it conjectured that the number of voids may increase with an increase in the number of Ni powder particles, resulting in the increased permeability observed in this study.

\section{Conclusions}

Epoxy coatings containing various amounts of particulate Ni powder and flaky Al powder were applied to electrogalvanized steel, and their corrosion behavior was examined by immersing specimens in an aqueous solution containing $100 \mathrm{ppm}$ formic acid, $100 \mathrm{ppm}$ acetic acid and $83 \mathrm{ppm} \mathrm{NaCl}$ at $40^{\circ} \mathrm{C}$ for $350 \mathrm{~h}$. From the distribution analysis of the $\mathrm{Ni}$ and $\mathrm{Al}$ powders in the coatings, gas permeation measurements of the coatings and characterization of the corroded samples, the following conclusions were drawn.

(1) The addition of $\mathrm{Al}$ powder improves the corrosion resistance of the coatings containing any amount of $\mathrm{Ni}$ powder $(0,20,40$ and $70 \mathrm{phr} \mathrm{Ni})$.

(2) Severe corrosion of the $\mathrm{Zn}$ layer occurs near a $\mathrm{Ni}$ powder particle because of galvanic corrosion. However, flaky $\mathrm{Al}$ powder is often located near the $\mathrm{Zn}$ /coating interface, preventing direct contact between the Ni powder and the $\mathrm{Zn}$ layer, particularly when the added amount of $\mathrm{Al}$ is high ( $\geq 40 \mathrm{phr} \mathrm{Al})$, and this results in improved corrosion resistance.

(3) Although the Ni powder increases gas permeability by introducing voids in the coating, the flaky $\mathrm{Al}$ powder greatly reduces both oxygen and water vapor permeability by the labyrinth effect. This reduction of permeability probably also contributes to improved corrosion resistance.

\section{REFERENCES}

1) Recycling Target for End-of-life Vehicles,METI, Industrial Structure Council and Automobile Disposal and Recycling Subcommittee, Ministry of Economy, Trade and Industry, Tokyo, (1996).

2) S. Suzuki, H. Ogata, S. Umino and C. Kato: Tetsu-to-Hagané, 89 (2003), 1.

3) M. Nakamura and Y. Yamamoto: Technical Paper of Society of Automotive Engineers of Japan, Vol. 956, Society of Automotive Engineers of Japan, Tokyo, (1995), 221.

4) T. Mizuguchi, R. Abe and Y. Makoto: Curr. Adv. Mater. Process., 6 (1993), 1539.

5) M. Fuda, T. Izaki and T. Omori: Curr. Adv. Mater. Process., 10 (1997), 1237.

6) M. Sagiyama and N. Morito: Tetsu-to-Hagané, 81 (1994), 401.

7) T. Watanabe, Y. Shindou, T. Shiota, K. Yamato and S. Nomura: Proc. Int. Conf. on Zinc and Zinc Alloy Coated Steel Sheet (Galvatech '89), ISIJ, Tokyo, (1989), 80 .

8) J. Oka and H. Iwakura: Tetsu-to-Hagané, 73 (1987), 2235.

9) H. Ogata, S. Suzuki and K. Mochizuki: Kawasaki Steel Giho, 32 (2000), 21.

10) H. Ogata, S. Suzuki, S. Umino and K. Mochizuki: SAE Technical Paper, Paper No. 2000-01-0307, SAE International, Warrendale, PA, (2000).

11) H. Yoshida, K. Arai, M. Hirata and H. Akimichi: Vacuum, 86 (2012), 838 .

12) A. R. Marder: Prog. Mater. Sci., 45 (2000), 191.

13) F. Mansfeld, D. H. Hengsten and J. V. Kenkel: Corrosion, 30 (1974), 343.

14) X. J. Raj and T. Nishimura: J. Mater. Eng. Perform., 25 (2016), 474.

15) D. L. Zhang, W. Wang and Y. Li: Corros. Sci., 52 (2010), 1277.

16) R. M. Souto, Y. Gonzalez-Garcia, A. C. Bastos and A. M. Simoes: Corros. Sci., 49 (2007), 4568.

17) A. M. Simoes, A. C. Bastos, M. G. Ferreira, Y. Gonzalez-Garcia, S. Gonzalez and R. M. Souto: Corros. Sci., 49 (2007), 726.

18) J. B. Bajat and V. B. Miskovic-Stankovic: Prog. Org. Coat., 49 (2004), 183. 